\title{
Hybridization between Yellow-billed Cardinal Paroaria capitata and Red-crested Cardinal P. coronata in southern Argentina
}

\author{
Luciano N. Segura ${ }^{1,4}$, Federico A. De Maio ${ }^{2} \&$ Mauricio Failla $^{3}$ \\ Sección Ornitología, Museo de La Plata, Universidad Nacional de La Plata-Conicet, La Plata, Buenos Aires, Argentina. \\ Centro de Investigaciones y Transferencia, Universidad Nacional de Río Negro, Viedma, Río Negro, Argentina. \\ Proyecto Patagonia Noreste, Balneario El Cóndor, Río Negro, Argentina. \\ 4 Corresponding author: luchosegura79@gmail.com
}

Received on 26 February 2019. Accepted on 28 June 2019.

\begin{abstract}
The genus Paroaria is a group of conspicuous songbirds widely distributed in South America that has been studied recently to delimit its species and establish their phylogenetic relationships. Although hybridization has been reported between the most phylogenetically related species of the genus, we here present a case of hybridization between the Yellow-billed Cardinal $(P$. capitata) and Red-crested Cardinal (P. coronata) for the first time, two phylogenetically unrelated members of the group. This data contributes to the knowledge of this avian group whose systematics is still under debate.
\end{abstract}

KEY-WORDS: breeding biology, hybrids, interbreed, Neotropical birds, Patagonia

Species delimitation has been a crucial topic in the natural history of birds, both for systematic and ecological studies (de Queiroz 2007). Systematic studies on the genus Paroaria, a group of conspicuous songbirds widely distributed in South America (Jaramillo 2011), indicate that it comprises six to eight species splitted into two ecological groups: the riparian species (P. gularis, $P$. baeri, $P$. xinguensis, $P$. capitata, $P$. cervicalis and $P$. nigrogenis) and the open-forest species ( $P$. coronata and $P$. dominicana) (Dávalos \& Porzecanski 2009). Estimated divergence times range from 3.7 to 5.0 mya for the split between the open-forest $v$ s. riparian clades, which has led them to show at present both morphological (Jaramillo 2011) and genetic (Dávalos \& Porzecanski 2009, Areta et al. 2017) differences. During the last decades, it has been reported some natural hybridization between species of this genus, for example between P. baeri and P. gularis (Jaramillo 2011, Lopes \& Gonzaga 2013, Areta et al. 2017), two non-sister species but still phylogenetically close "riverines" (Dávalos $\&$ Porzecanski 2009). However, in captivity conditions, hybridization has also been reported among less related Paroaria species ( $P$. dominicana and $P$. nigrogenis, two genetically distant species; McCarthy 2006) and even with species of other genera and even families (P. coronata with Sicalis flaveola, Gubernatrix cristata, Cardinalis cardinalis, Chrysomus ruficapillus and Molothrus bonariensis; McCarthy 2006). In this contribution, we present the first record of natural hybridization between
Yellow-billed and Red-crested Cardinal (a riverine and an open-forest cardinal respectively, two phylogenetically distant species in Paroaria).

This study was conducted at Viedma, Río Negro province, northeastern Patagonia, Argentina ( $40^{\circ} 48^{\prime} \mathrm{S}$; $63^{\circ} 01^{\prime} \mathrm{W}$; Fig. 1). The study area is representative of the "Monte" ecoregion (Brown et al. 2006), with large areas of native xerophytic vegetation altered by extensive and low-density cattle grazing. This region is characterized by warm summers (maximum temperature of $42.3^{\circ} \mathrm{C}$ ) and cold winters (minimum temperature of $-13.5^{\circ} \mathrm{C}$ ), with most precipitations occurring between November and March. The National Meteorological Survey of Argentina from 1987-2017 reports mean annual rainfall as $257 \mathrm{~mm}$ and mean annual temperature as $15^{\circ} \mathrm{C}$. At the local scale, the nesting territory was located on the southern margin of the Negro River, in a wetland dominated by the exotic Salix viminalis (Salicaceae). The area was surveyed every 5-8 days, since the first evidence of hybridization, with the help of binoculars and photographic cameras.

In March 2016 (end of 2015-2016 breeding season) we located an interspecific pair moving together in the nesting area (Fig. 2A). We inspected the surroundings shrubs and forests to locate the nest (see details in Segura et al. 2015), but we could not find it. On 18 April, we saw both parents with a fledgling for the first time (Fig. 2B $\& \mathrm{C})$ and delivering food to it. We observed the family group until the beginning of June, and since then, we 


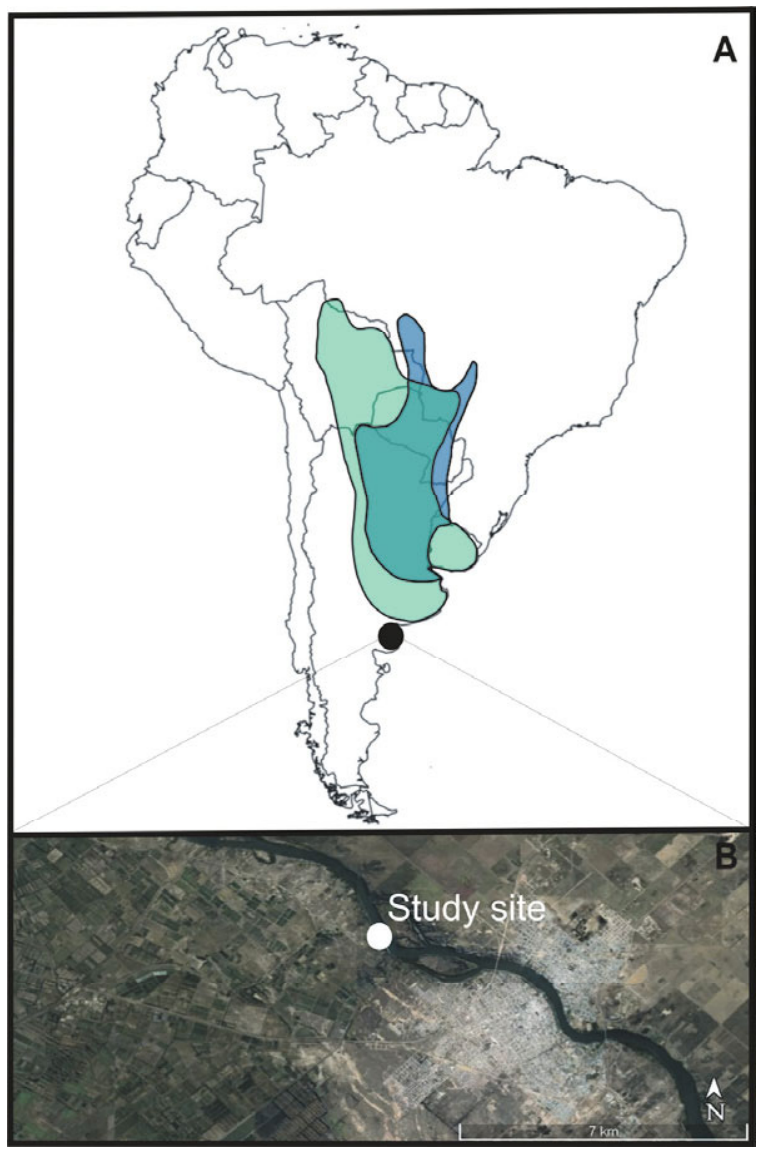

Figure 1. Distribution area of the Yellow-billed Cardinal Paroaria capitata (blue shaded) and Red-crested Cardinal $P$. coronata (green shaded) in South America (A); Jaramillo 2011). Area surveyed in this study (B). detected only adults throughout the winter, until spring began. The size and plumage of our hybrid juvenile (Fig. 2D) strikingly resembled that of $P$. capitata juveniles (Fig. $2 \mathrm{E})$, although the bill color and tarsus were gray, like $P$. coronata.

In the last decades, individuals of both species have been reported in atypical southern localities in relation to the original distribution (Fig. 1). For example, on web platforms such as EcoRegistros (2018) or eBird (2018), the records of both species in the Negro River (northern Patagonia) and cities in southern Buenos Aires province (central-eastern Argentina) are increasingly frequent. A possible explanation is that both species are traditionally captured and sold in illegal trade in a large fraction of their distribution area (UNEP-WCMC 2009), and the release of individuals from captivity in areas near urban centers would explain this atypical distribution.

The sympatry area between both species is extensive (Fig. 1) and the contact is not recent (Dávalos \& Porzecanski 2009, Areta et al. 2017). However, no hybrids have been reported within this area. On the one hand, this lack of previous reports could be simply due to an artifact of poor sampling, but considering that both species are conspicuous and relatively common in their respective habitats, it is unlikely that this could be the reason. However, there may be some behavioural or ecological barriers within their sympatry area (Randler 2006) that keep them from hybridizing in a natural way. Although our birds paired and reproduced in natural conditions, we

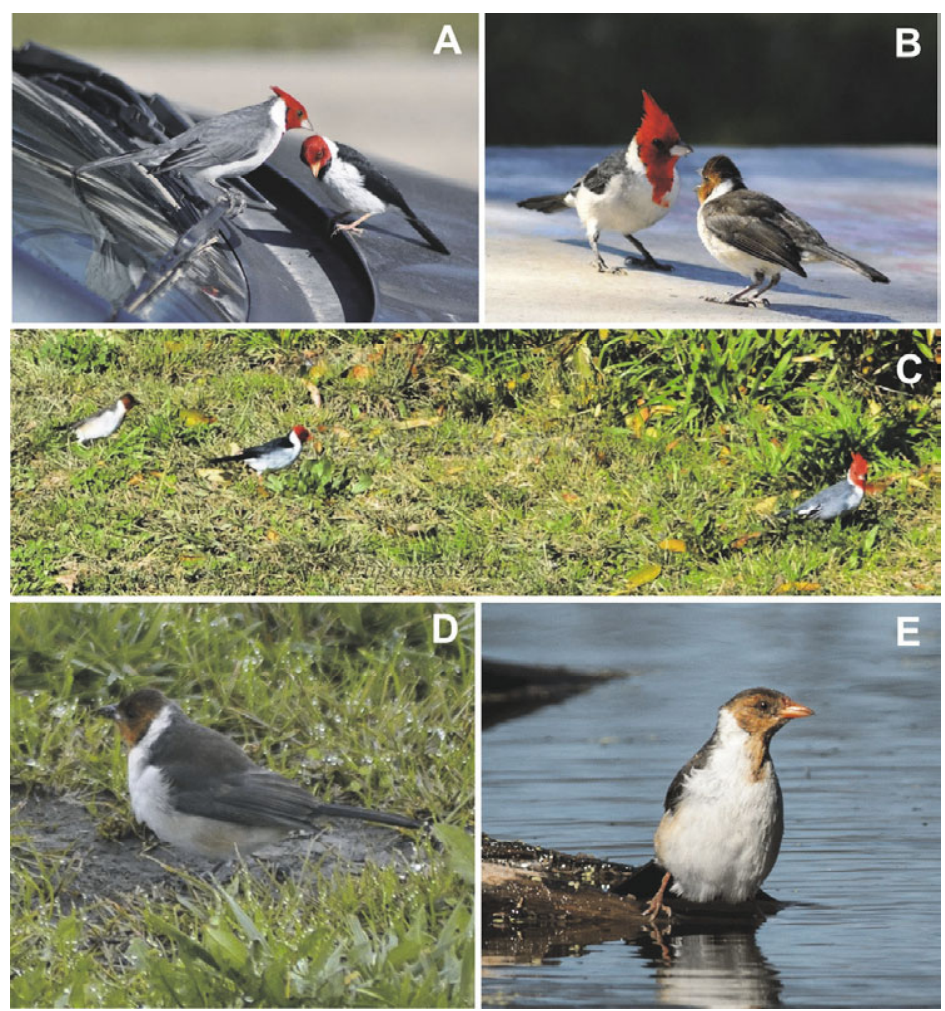

Figure 2. Mixed breeding pair composed by a Yellow-billed Cardinal, Paroaria capitata, and a Red-crested Cardinal, P. coronata (A). Red-crested Cardinal feeding the hybrid fledging (B). Familiar group moving together on the ground (C). The hybrid fledging (D). A pure Yellow-billed fledging (E). Photo authors: Graciela Balda (A, B, D), Eugenio Sicardi (D), Giselle Mangini (E). 
do not ignore the particular situation regarding the lack of conspecifics in an unusual austral distribution area for both species, which could have favored the interspecific hybridization (see Baker 1996).

It has been discussed that genetic differences between the related $P$. capitata and $P$. cervicalis (and even $P$. gularis) are so small that cases of hybridization are expected (Dávalos \& Porzecanski 2009), but $P$. capitata and $P$. coronata are more divergent (Dávalos \& Porzecanski 2009, Areta et al. 2017). In this sense, phylogenetic results within Paroaria indicate that the mitochondrial gene tree contained a deep split between open-forest $(P$. dominicana and $P$. coronata) and riparian species (all other Paroaria). Our results show that, despite this genetic split, they still maintain the ability of interbreeding as an ancestral condition (see Podos \& Nowicki 2004).

Even though we cannot infer if the hybrid offspring has post-zygotic barriers to freely interbreed with the parental species, the fact that two genetically distant Paroaria may naturally hybridize, as first reported here, may be an additional evidence that tropical bird species, and Paroaria species in particular, may hold the potential to mate and interbreed for a very long time after speciation (Weir \& Price 2011, Areta et al. 2017). The genus Paroaria, therefore, may represent an interesting system to further research on the role of hybridization on the evolution and speciation of birds.

\section{ACKNOWLEDGEMENTS}

We thank Martín Méndez, Graciela Balda and Eugenio Sicardi for help in data collection, and Facundo X. Palacio and an anonymous reviewer for helpful comments on a previous version of this manuscript. L.N.S. is a CONICET Research Fellow.

\section{REFERENCES}

Areta J.I, Dornas T., Kirwan G.M., Araújo-Silva L.E. \& Aleixo A. 2017. Mixing the waters: a linear hybrid zone between two riverine Neotropical cardinals (Paroaria baeri and P. gularis). Emu 117: 40-50.

Baker M.C. 1996. Female buntings from hybridizing populations prefer conspecific males. Wilson Bulletin 108: 771-775.

Brown A.D., Martínez-Ortíz U., Acervi M. \& Corcuera J. 2006. Situación ambiental Argentina 2005. Buenos Aires: Fundación Vida Silvestre Argentina.

Dávalos L.M. \& Porzecanski A.L. 2009. Accounting for molecular stochasticity in systematic revisions: species limits and phylogeny of Paroaria. Molecular Phylogenetics and Evolution 53: 234-248.

de Queiroz K. 2007. Species concepts and species delimitation. Systematic Biology 56: 879-886.

eBird. 2018. eBird: an online database of bird distribution and abundance. http://www.ebird.org (Access on 26 December 2018).

EcoRegistros. 2018. Cardenilla (Paroaria capitata) and Cardenal Común (Paroaria coronata). http://www.ecoregistros.org (Access on 26 December 2018).

Jaramillo A. 2011. Genus Paroaria, p. 642-644. In: del Hoyo J., Elliott A. \& Christie D.A. (eds.). Handbook of the birds of the world, v. 16 (tanagers to New World blackbirds). Barcelona: Lynx Editions.

Lopes L.E. \& Gonzaga L.P. 2013. Taxonomy, natural history, and conservation of Paroaria baeri (Aves: Thraupidae). Tropical Zoology 26: 87-103.

McCarthy E.M. 2006. Handbook of avian hybrids of the world. Oxford: Oxford University Press.

Podos J. \& Nowicki S. 2004. Beaks, adaptation, and vocal evolution in Darwin's Finches. BioScience 54: 501-510.

Randler C. 2006. Behavioural and ecological correlates of natural hybridization in birds. Ibis 148: 459-467.

Segura L.N., Mahler B., Berkunsky I. \& Reboreda J.C. 2015. Nesting biology of the Red-crested Cardinal (Paroaria coronata) in south temperate forests of central Argentina. Wilson Journal of Ornithology 127: 249-258.

UNEP-WCMC. 2018. UNEP-WCMC Species Database: CITES-listed species. http://www.unep-wcmc.org (Access on 28 December 2018).

Weir J.T. \& Price T.D. 2011. Limits to speciation inferred from times to secondary sympatry and ages of hybridizing species along a latitudinal gradient. American Naturalist 177: 462-469.

Associate Editor: Fábio R. Amaral. 